Proceedings of the International Symposium on Physics of Materials (ISPMA 14), September 10-15, 2017, Prague

\title{
Center Line Segregation in Twin-Roll Cast AZ31 Magnesium Alloy
}

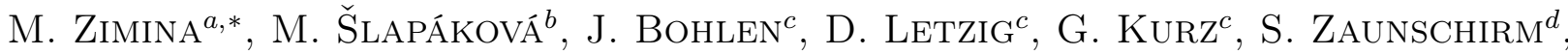 \\ J. KAStner ${ }^{d}$ AND M. CIESLAR ${ }^{b}$

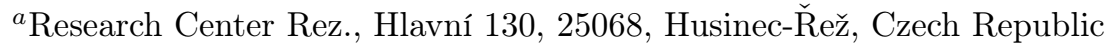 \\ ${ }^{b}$ Charles University, Faculty of Mathematics and Physics, Ke Karlovu 5, 12116, Prague, Czech Republic \\ ${ }^{c}$ Magnesium Innovation Centre (MagIC) Helmholz Zentrum Geesthacht, \\ D21502 Max-Planck Str. 1, Geesthacht, Germany \\ ${ }^{d}$ University of Applied Sciences Upper Austria, Stelzhamerstr. 23, 4600 Wels, Austria
}

\begin{abstract}
A three-dimensional approach to microstructural investigations was for the first time applied to a continuous cast material in order to understand solidification processes and liquid flow during casting. A twin-roll cast AZ31 magnesium alloy strip was subjected to observations by light optical microscopy, electron microscopy, and X-ray microtomography. The last one is found to be the only suitable for the 3D characteristic of the segregation channels containing $\mathrm{Mn}$ and Al-rich primary phases located in the central zone of the strip. It was shown that a reliable three-dimensional image of the volume containing central line segregation cannot be obtained using conventional metallographic methods, whereas X-ray microtomography allows the complete reconstruction of major features of the central segregation in the alloy.
\end{abstract}

DOI: 10.12693/APhysPolA.134.774

PACS/topics: 61.72.Dd, 61.72.Ff, 61.72.Qq, 61.66.Dk, 81.05.Zx

\section{Introduction}

Modern industry requires production of lightweight materials with enhanced microstructure and mechanical properties. In automotive and aerospace industries weight is a crucial parameter, thus, aluminum and magnesium based alloys are the most favorable metallic materials. The development of reliable new casting routines is very important in terms of reducing possible defects, such as cracks, porosity, tears and segregation [1]. The formation of these defects leads usually to a premature fracture as well as to a reduced strength [2] and can influence the fatigue behavior [3]. During twin-roll casting (TRC) the molten metal solidifies firstly at surfaces close to the rolls and then the heat is transferred by conduction. An existence of non-contact points due to the solidification shrinkage and entrapped gas leads to the heat transfer via a gas layer between metal and rolls. Deformation induced during the ongoing solidification process leads to the excess of defects mainly in the center of the strip [4]. For magnesium and aluminum, the TRC is well-developed and allows a production of high quality thin strips $[5,6]$. However, an establishment of appropriate casting conditions varies for varied materials and is time consuming. The influence of the casting speed, cooling rate, temperature of the melt and other parameters on the final microstructure and a presence of a center line segregation (CLS) is very significant. Con-

${ }^{*}$ corresponding author; e-mail: m.zimina@seznam.cz ventional TRC $\mathrm{Mg}-3 \mathrm{Al}-1 \mathrm{Zn}$ alloy exhibits severe inverse and central segregation of solute $\mathrm{Al}$ and $\mathrm{Zn}$ atoms due to its rather wide solidification range. The role of the segregation on tensile properties of magnesium alloys was studied by several authors $[7,8]$. Thus, an exact characterization of the segregation of secondary-phase particles becomes more important for the alloys production and can help to optimize casting conditions.

There are several conventional methods developed for a microscopic study of the center line segregation. Light optical microscopy (LOM) is suitable for the determination of defects and their sizes. However, the identification of phase composition and its distribution in the material is feasible only using energy-dispersive X-ray spectroscopy (EDS). An EDS system is usually integrated to scanning or transmission electron microscopes (TEM or SEM) and is a very effective and accessible technique. Sample preparation for those two methods is relatively simple and is well-established for most alloys. LOM and electron microscopy can provide very proper microstructural information. However, they are limited to smallscale regions of samples and they are not suitable for receiving general information about the whole volume of the material. Thus, the penetration into the middle of the strip in order to study the CLS needs novel 3D approaches. A combination of electron microscopy with focused ion beam (FIB) technique creates a high-resolution three-dimensional image of the material, however, this procedure gradually destroys the specimen [9]. X-ray microtomography belongs to the class of nondestructive 3 D material characterization techniques at a micron level spatial resolution $[10,11]$. This method does not require any time-consuming specimen preparation and al- 
lows many scans of the same specimen under different conditions to be made. The technique is complementary to higher resolution $2 \mathrm{D}$ microscopy and lower resolution 3D ultrasonic imaging. Primarily, X-ray tomography is commonly used for medical application but in the recent decade it was employed as a tool for the microstructural studies of ceramics [12], foams [13] and alloys [14, 15].

In this study X-ray tomography was for the first time used for the investigation of the CLS in a TRC AZ31 magnesium alloy strip. Results were compared with LOM and SEM observations.

\section{Experimental}

A twin-roll cast AZ31 magnesium alloy strip of a $5.6 \mathrm{~mm}$ thickness with chemical composition given in Table I was used in this study. Specimens were cut from the strip, mechanically ground, polished and subjected to light and electron microscopy investigations. Micrographs of specimens in transverse (TD), rolling (RD) and normal (ND) directions were obtained using an Olympus GX51 light optical microscope and FEI Quanta FEG electron microscope. Specimens for X-ray computed tomography (CT) were directly cut from the strip without any additional preparation. Series of 2D X-ray absorption images were recorded during rotation of the object with small angular steps. Projection images were captured and used for the generation of a three-dimensional digital image where each voxel (volume element) represents the X-ray absorption in this point [16]. Because of a relationship between X-ray absorption and material composition and density, the 3D internal structure can be derived and the resulting 3D images can be displayed as series of $2 \mathrm{D}$ "slices".

For CT investigations [17] a Nanotom 180NF desktop device from General Electric with a $180 \mathrm{keV}$ nanofocus tube with transmission target and external liquid cooling system for measurement stabilization and $2316 \times 2316$ pixel Hamamatsu flat panel detector were used. Scan parameters were $95 \mathrm{keV}$ with a $0.1 \mathrm{~mm}$ copper pre-filter and $223 \mu \mathrm{A}$. The achieved voxel size was $(0.68 \mu \mathrm{m})^{3}$. For the image reconstruction, the software Datos $\mid \mathrm{x} 2$ reconstruc- tion 2.2.1 was used in a combination with a $3 \times 3$ inline median filter and a beam hardening correction. VGStudio MAX 2.2 was used for visualization and evaluation. A $9 \times 9 \times 9$ median filter was applied for the noise elimination. The surface near the examined region was excluded from evaluation in order to reduce the influence of artefacts. The advanced surface determination was used for the detection of particles with higher absorption, whereby the starting value of the surface determination was chosen to be $\mu+3.5 \sigma . \mu$ is an expected value of the Gaussian distribution from the material matrix and $\sigma$ is the standard deviation.

TABLE I

Chemical composition [wt.\%] of AZ31 magnesium alloy.

\begin{tabular}{c|c|c|c|c|c|c}
\hline \hline $\mathrm{Al}$ & $\mathrm{Zn}$ & $\mathrm{Mn}$ & $\mathrm{Ca}$ & $\mathrm{Cu}$ & $\mathrm{Fe}$ & $\mathrm{Mg}$ \\
\hline 3.45 & 0.98 & 0.28 & 0.002 & 0.002 & 0.004 & bal.
\end{tabular}

\section{Results and discussion}

Micrographs of polished surfaces viewed in three main directions are shown in Fig. 1. Coarse particles (marked by circles (a) and rectangle (b)) are distributed inside the $\mathrm{Mg}$ matrix with higher density in the central zone of the cross-section of the strip spaced nearly equidistantly in the section perpendicular to RD with about $2 \mathrm{~mm}$ step (Fig. 1a). In sections perpendicular to TD (Fig. 1b) no periodicity of the primary particle distribution is observed. Attempts to visualize segregated zones in the sections perpendicular to ND failed because welldeveloped dendritic structure typical for these types of alloys [18] reduces the visibility of segregated particles on sections prepared from the central area of the strip (Fig. 1c). Thus, the shape and distribution of these particles in this direction is not clear.

Figure 2 shows BSE images of the AZ31 alloy in sections perpendicular to three casting directions. In RD (Fig. 2a) the periodicity of secondary particles found by LOM is confirmed while in TD and RD sections (Fig. 2b, c) segregated channels elongated in the RD appear.
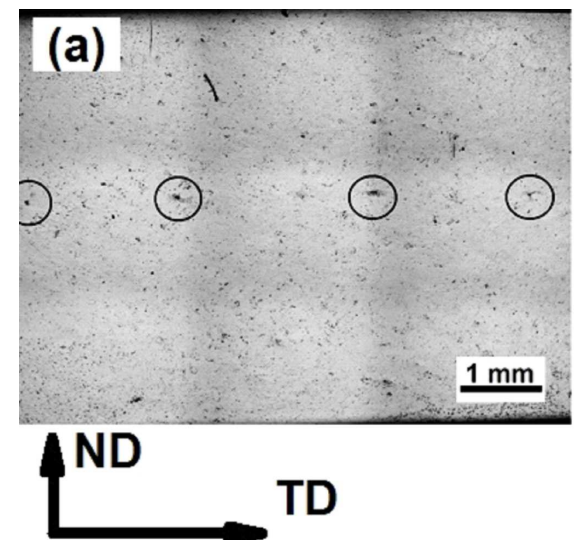
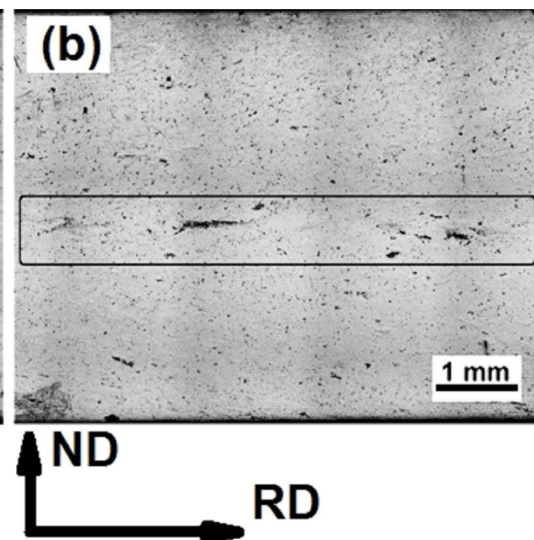

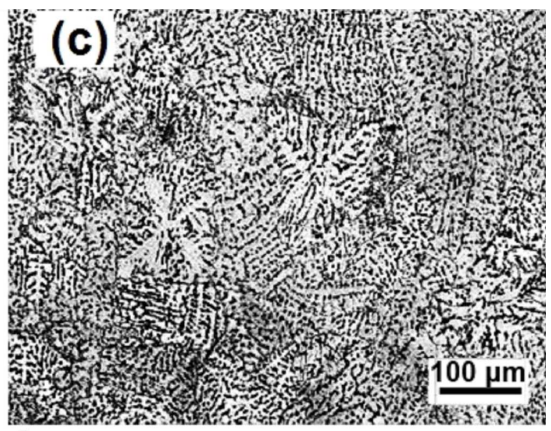

TD

Fig. 1. Microstructure images of a twin-roll cast AZ31 magnesium alloy observed in (a) rolling, (b) transverse, and (c) normal directions using light optical microscopy. Part (c) shows developed dendritic structure of the strip section in the central plane of the strip. 

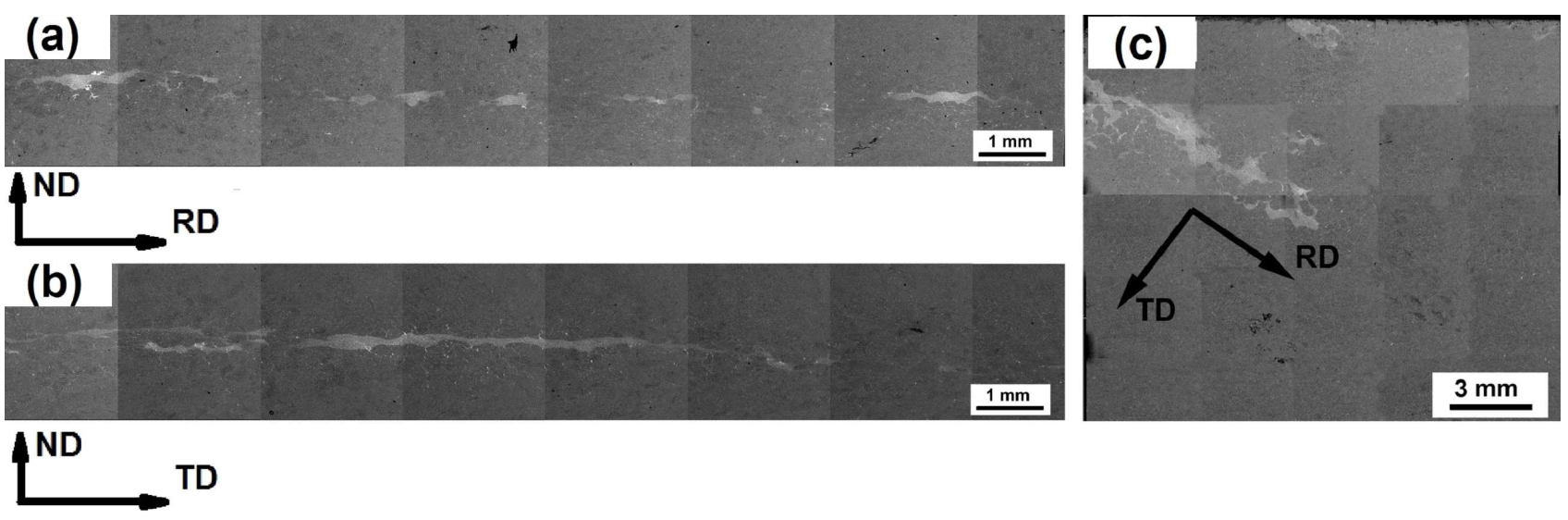

Fig. 2. Backscatter electron images of a twin-roll cast AZ31 magnesium alloy in sections perpendicular to (a) rolling, (b) transverse, and (c) normal directions in the center of the strip.
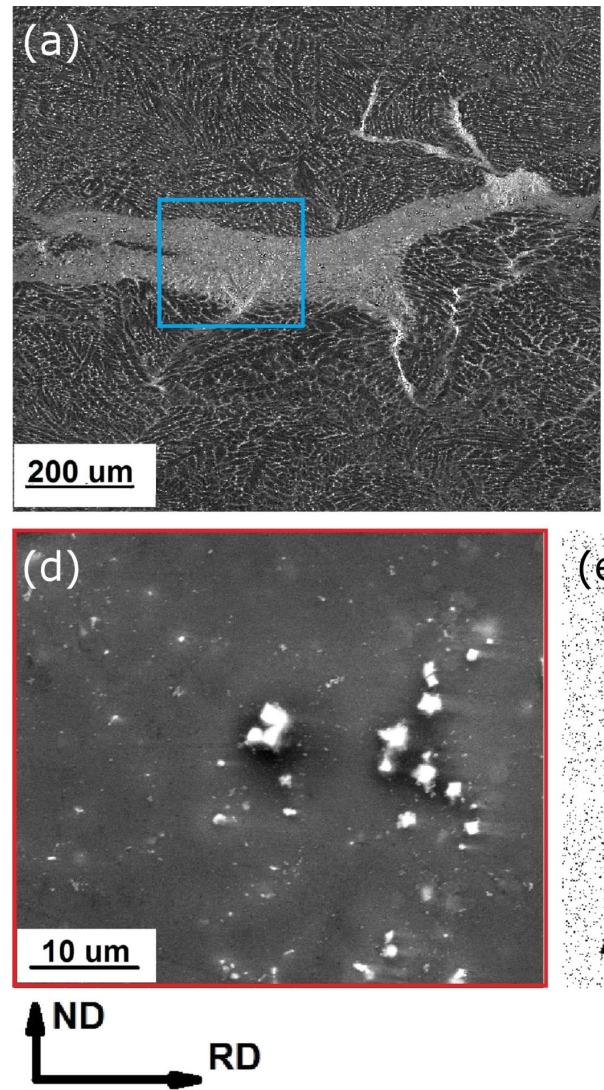

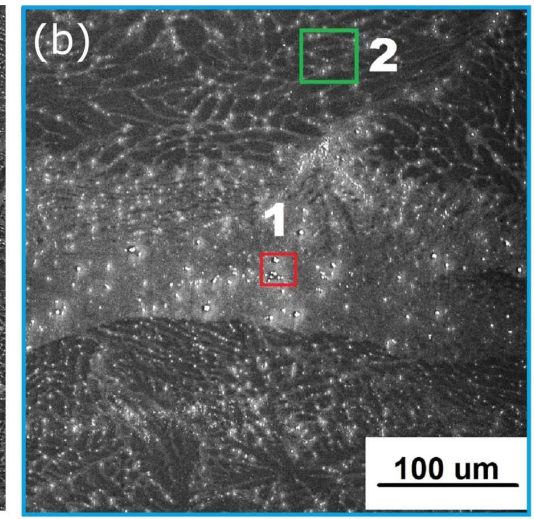

(e)

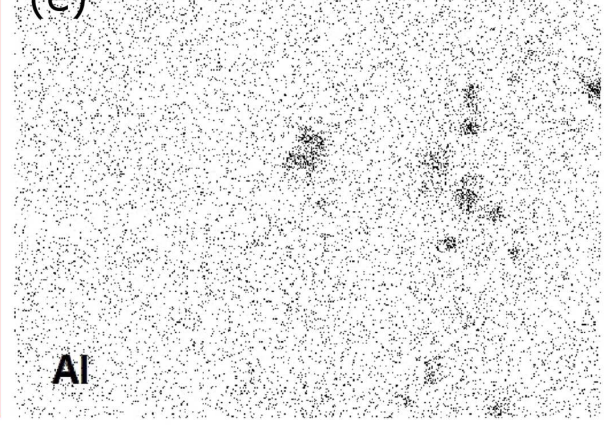

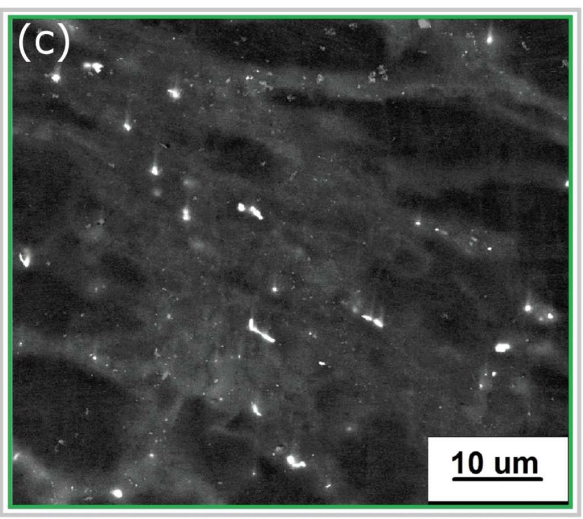

(f)

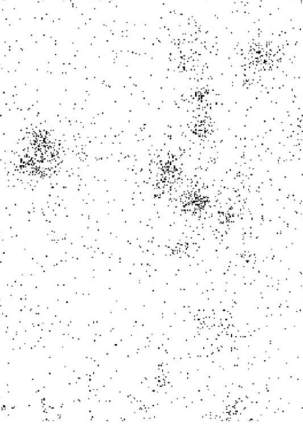

Fig. 3. SEM images of the central region of the as-cast AZ31 strip: (a,b) BSE image, (c,d) SE of the dendritic structure and coarser particles, respectively, (e) and (f) EDS maps of $\mathrm{Al}$ and $\mathrm{Mn}$ from the region shown in part (c).

A more complex sample preparation, namely removing of the upper half of the strip and imaging of only a central part of the strip in the ND leads to an incomplete mapping of the segregation inside the specimen (Fig. 2c), because the thickness of the center-line segregation does not exceed $50 \mu \mathrm{m}$ and, therefore, is very often removed during polishing. Moreover, as it is shown in Fig. 1a, b, segregations are located not exactly at the center of the strip but their position varies along the strip length which makes the observations in ND statistically less accurate.

Nevertheless, SEM allows the identification of the composition of secondary particles using EDS. Figure 3 shows SEM images of the central zone viewed in TD. EDS analysis in Fig. 3d of a dendritic structure marked in Fig. 3b by box one shows that it consists mainly of $\beta-\mathrm{Mg}_{17} \mathrm{Al}_{12}$ primary particles that can be dissolved 
during annealing at temperatures above $440^{\circ} \mathrm{C}$ [19]. An area marked by a box two in Fig. 3b contains coarser particles. Figure 3e,f show that mainly aluminum and manganese from thermally very stable intermetallic compounds $\mathrm{Al}_{8} \mathrm{Mn}_{5}$ and $\mathrm{Al}_{11} \mathrm{Mn}_{4}$ [20] are present in this region.

The SEM technique is irreplaceable for the identification of the composition of primary phase particles, however the collected information does not provide a $3 \mathrm{D}$ insight of the distribution of particles in the volume of the strip after casting.

\subsection{X-ray tomography}

Recently, synchrotron X-ray tomography was used for the study of a dendritic structure of several magnesium alloys by Yang et al. [21]. Using the combination of Xray tomography and computer simulations the preferred growth orientations of the dendrites were described. A similar principle can be used for the investigation of the central segregation present in TRC AZ31 magnesium alloy. Figure 4 shows 3D reconstructed patterns of sec- ondary phase particles in the central region. The information about the distribution of particles is more complex than the data obtained by LOM and SEM. Much larger area of the specimen is scanned by this method and the periodicity of segregation lines is clearly visible (Fig. 4b,c), while this information is missing in SEM and LOM. The distance between segregation lines (about $2 \mathrm{~mm}$ ) is similar to the one described by Birol [22] in several aluminum alloys. Segregated channels consist mainly of eutectic phases implying thus an enrichment of the liquid central fraction of the material during solidification. The enriched mushy zone is then squeezed between already solidified skins and forced to flow in the direction opposite to the casting direction. Finally, the liquid is trapped by the two skins when they weld together in some points close to the center of the strip leading to the formation of well-defined solute mid channels. Figure $4 \mathrm{~d}$ shows that the distribution of $\mathrm{Al}-\mathrm{Mn}$ and $\mathrm{Mg}_{17} \mathrm{Al}_{12}$ intermetallic particles is not homogeneous along the RD, because of minor changes in the casting rate leading to changes in the recrystallization rate [2]. (a)

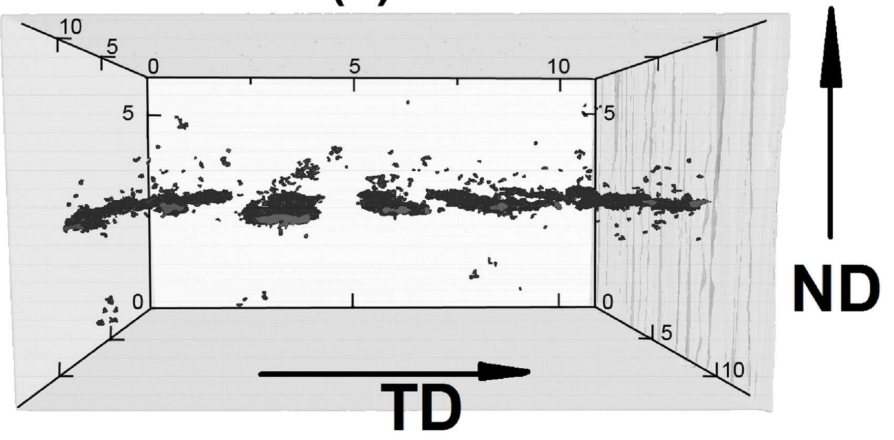

(c)

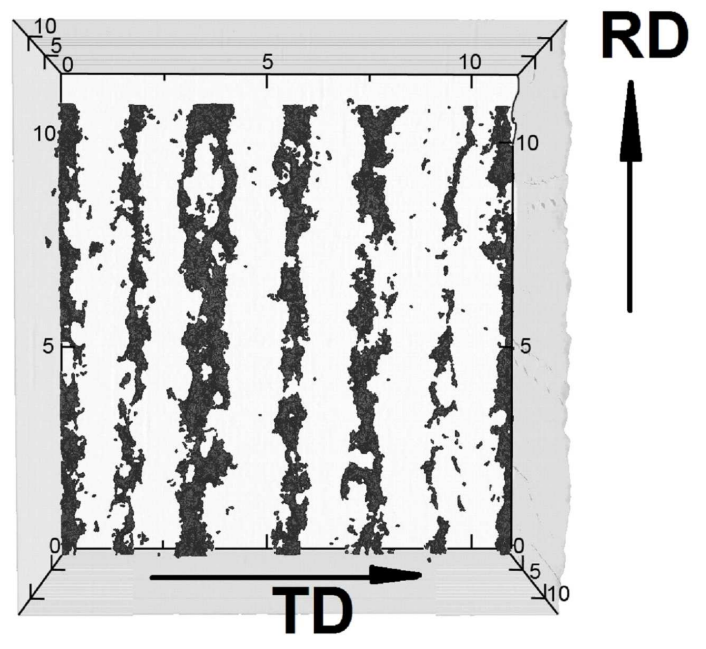

(b)

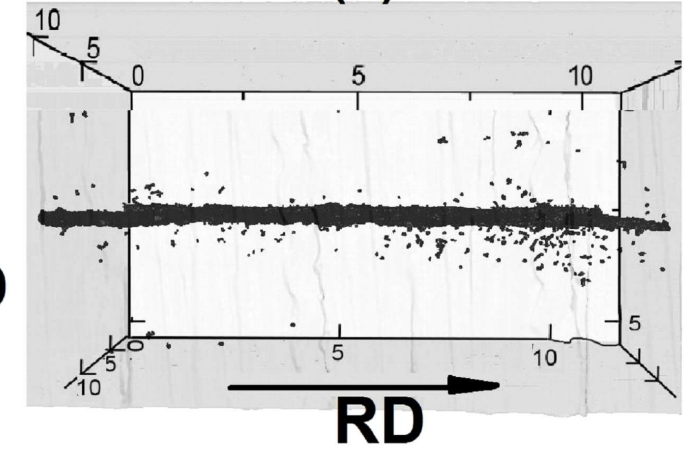

(d)

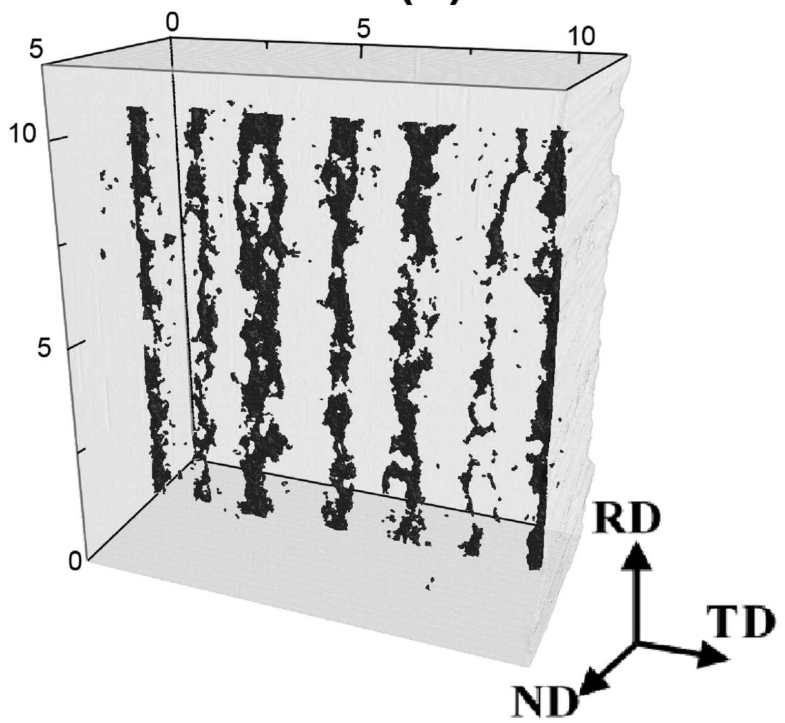

Fig. 4. 3D reconstructed patterns of central segregation in TRC AZ31 magnesium alloy in different perspectives: (a) $\mathrm{RD}$, (b) TD, (c) ND and (d) general view. Scale is represented in millimeters. 


\section{Conclusions}

A $5.6 \mathrm{~mm}$ thick AZ31 magnesium alloy strip was produced by TRC. The morphology, shape and composition of segregated primary phase particles located in the center of the strip were investigated by different techniques. It was shown that the use of conventional methods, such as LOM and SEM, requires preparation of several samples in three casting directions (RD, TD, ND). They do not allow obtaining a reliable three-dimensional image of segregated phases. X-ray tomography is a more appropriate technique for the study of primary phase particles distribution which allows reconstruction of the whole volume containing central segregation in TRC AZ31 magnesium alloy. This technique can be also successfully used for the investigation of the dendritic structure occurring in different alloys.

\section{Acknowledgments}

The authors are grateful to the financial support under the project MSMT No. 7AMB17AT046 and to the Grant Agency of Charles University in Prague (Grant No. 946213). Stefan Zaunschirm and Johann Kastner thank FFG, the governments of Upper Austria and Styria for the support of the K-Project ZPT+.

The presented work was financially supported by the Ministry of Education, Youth and Sport Czech Republic - project LQ1603 Research for SUSEN. This work has been realized within the SUSEN Project (established in the framework of the European Regional Development Fund (ERDF) in project CZ.1.05/2.1.00/03.0108 and of the European Strategy Forum on Research Infrastructures (ESFRI) in the project CZ.02.1.01/0.0/0.0/15_008/0000293, which is financially supported by the Ministry of Education, Youth and Sports.

\section{References}

[1] A.K. Dahle, D.H. StJohn, Acta Mater. 47, 31 (1998).

[2] S. Das, N.S. Lim, J.B. Seol, H.W. Kim, C.G. Park, Mater. Des. 31, 1633 (2010).

[3] Q.G. Wang, D. Apelian, D.A. Lados, J. Light Met. 1, 73 (2001).
[4] S.S. Park, W.J. Park, C.H. Kim, B.S. You, N.J. Kim, JOM 61, 14 (2009).

[5] G. Kurz, J. Bohlen, L. Stutz, D. Letzig, K.U. Kainer, in: Magnesium Technology 2013, Eds. N. Hort, S.N. Mathaudhu, N.R. Neelameggham, M. Alderman, Springer, Cham 2013, p. 363.

[6] M. Poková, M. Zimina, M. Cieslar, Acta Phys. Pol. A 128, 746 (2015).

[7] J.H. Bae, M.S. Shim, B.C. Suh, D.W. Kim, S.H. Park, N.J. Kim, Mater. Lett. 132, 361 (2014).

[8] S.S. Park, G.T. Bae, D.H. Kang, I.-H. Jung, K.S. Shin, N.J. Kim, Scr. Mater. 57, 793 (2007).

[9] C.A. Volkert, A.M. Minor, MRS Bull. 32, 389 (2007).

[10] E.N. Landis, D.T. Keane, Mater. Character. 61, 1305 (2010).

[11] S.R. Stock, in: Micro Computed Tomography: Methodology and Applications, CRC press, Boca Raton 2008.

[12] H. Dunsmuir, P.B. Vandiver, R.R. Chlanelll, H.W. Deckman, J.H. Hardenbergh, MRS Proc. 352, 73 (2011).

[13] F. Buyens, S. Legoupil, A. Vabre, in: $C D$ Proc. Int. Symp. on Digital Industrial Radiology and Computed Tomography, Lyon, 2007.

[14] H.M.M.A. Rashed, J.D. Robson, P.S. Bate, B. Davis, Mater. Sci. Eng. A 528, 2610 (2011).

[15] M. Šlapáková Poková, M. Zimina, S. Zaunschirm, J. Kastner, J. Bajer, M. Cieslar, Mater. Character. 118, 44 (2016).

[16] G.T. Herman, in: Image Reconstruction from Projections: The Fundamentals of Computerized Tomography, Academic Press, New York 1980.

[17] J. Kastner, S. Zauschirm, S. Baumgartner, G. Requena, H. Pinto, G. Garces, in: 11th Europ. Conf. on Non-Destructive Testing, Prague, 2014, p. 163.

[18] A.K. Dahle, Y.C. Lee, M.D. Nave, P.L. Scha, D.H. St John, J. Light Met. 1, 61 (2001).

[19] M. Avedesian, H. Bakert, in: ASM Speciality Handbook: Magnesium and Magnesium Alloys, ASM International, New York 1999, p. 28.

[20] K. Braszczynska-Malik, in: Magnesium Alloys - Design, Processing and Properties, Eds. F. Czerwinski, InTech, 2011.

[21] M. Yang, S.M. Xiong, Z. Guo, Acta Mater. 92, 8 (2015).

[22] Y. Birol, J. Alloys Comp. 486, 168 (2009). 